\title{
Impact of nocturnal heart rate variability on cerebral small-vessel disease progression: a longitudinal study in community-dwelling elderly Japanese
}

\author{
Yoshitaka Yamaguchi, Manabu Wada, Hidenori Sato, Hikaru Nagasawa, Shingo Koyama, Yoshimi Takahashi, \\ Toru Kawanami and Takeo Kato
}

Recent evidence has shown an effect of ambulatory heart rate (HR) on cardiovascular events and mortality. Our objective was to determine whether ambulatory HR was related to the progression of cerebral small-vessel disease (SVD) or cognitive decline in community-dwelling elderly people. A cohort of 190 community-dwelling elderly people underwent an ambulatory blood pressure monitoring (ABPM), brain magnetic resonance imaging (MRI) and cognitive testing at baseline, with MRI and cognitive tests repeated 4 years later. HR variability in ABPM was quantified by the s.d. (s.d. and the root mean square of successive differences (RMSSD), and the relationship between HR variability and the progression of SVD/cognitive decline was investigated. We also assessed the association of nighttime HR variability and nocturnal HR dipping. The nighttime RMSSD of participants with the progression of SVD was significantly higher than that of those without progression of SVD $(P<0.05)$. Moreover, nighttime RMSSD was independently associated with the progression of SVD (1 b.p.m. increment: odds ratio $=1.13,95 \%$ confidence interval $=1.04-1.24, P<0.01$ ). We failed to confirm an association between cognitive decline and nighttime HR variability. However, s.d. in the daytime and 24-h HR were independently related to cognitive decline $(\boldsymbol{P}<0.05)$. Nocturnal HR dipping was least in the top quartiles of nighttime HR variability, with a monotonic trend of nocturnal HR dipping that was dependent on the quartiles of nighttime HR variability indices $(P<0.01)$. Increased HR variability during the night is a predictor of the progression of SVD in community-dwelling elderly people.

Hypertension Research (2015) 38, 564-569; doi:10.1038/hr.2015.38; published online 19 March 2015

Keywords: ambulatory blood pressure monitoring; blood pressure variability; cerebral small-vessel disease; cognitive decline; heart rate variability

\section{INTRODUCTION}

White matter lesions (WMLs) and lacunae, often visible on magnetic resonance imaging (MRI) in older persons, are generally regarded as having a vascular origin secondary to small-vessel disease (SVD) in the brain. ${ }^{1}$ Previous studies have indicated that SVD is common and ultimately results in cognitive and physical disabilities. ${ }^{2,3}$ On the basis of pathological and epidemiological studies, hypertension is considered to be the most important modifiable risk factor for SVD.

The prognostic importance of blood pressure (BP) is generally accepted for the prevention of an advanced SVD. High BP is closely associated with cerebrovascular disease; meanwhile, recent evidence has also shown that BP variability is linked to resistant hypertension. ${ }^{4}$ Furthermore, prior studies indicated BP variability as a potential risk factor for cardiovascular diseases ${ }^{5,6}$ and cerebral SVD. ${ }^{7}$ However, the association between resting heart rate (HR) and SVD remains unclear. Accumulating evidence has shown an association of ambulatory HR with vascular disease and mortality as follows: (1) ambulatory HR is an independent predictor of cardiovascular events and mortality ${ }^{8,9}$ and
(2) the absence of nocturnal HR dipping is an independent predictor of all-cause mortality. ${ }^{10}$

Over the past two decades and longer, many studies have been conducted to examine the relationship between ambulatory $\mathrm{BP}$ and risk for SVD. However, only a few studies have examined the association of SVD and ambulatory HR using a cross-sectional design. ${ }^{11-14}$ The association of ambulatory HR with the progression of SVD and cognitive decline in elderly persons has not yet been investigated in community-dwelling participants.

Therefore, we aimed to investigate this issue by examining the association of ambulatory HR, as evaluated by 24-h ambulatory BP monitoring (ABPM), with changes in SVD and global cognitive function in community-dwelling elderly Japanese people.

\section{METHODS}

\section{Study population}

The details of the present study design have been reported previously. ${ }^{7}$ All samples and data used for this study were obtained from 70 to 72 -year-old 


\begin{tabular}{|c|c|c|c|}
\hline \multicolumn{4}{|c|}{ Four areas of Sagae City } \\
\hline $\begin{array}{c}\text { Area } 1 \\
\text { All aged } 70 \text { years }\end{array}$ & $\begin{array}{c}\text { Area } 2 \\
\text { All aged } 71 \text { years }\end{array}$ & $\begin{array}{c}\text { Area } 3 \\
\text { All aged } 72 \text { years }\end{array}$ & $\begin{array}{c}\text { Area } 4 \\
\text { All aged } 70 \text { years }\end{array}$ \\
\hline$\downarrow$ & $\downarrow$ & $\downarrow$ & $\downarrow$ \\
\hline \multicolumn{4}{|c|}{$\begin{array}{l}490 \text { subjects were invited to undergo brain MRI, carotid artery ultrasonography, } \\
\text { and assessment of conventional risk factors and cognitive function }\end{array}$} \\
\hline & & \multicolumn{2}{|c|}{$\begin{array}{l}\text { Exclusion criteria } \\
\text { : MRI contraindicated } \\
\text { Refused MRI, ultrasonography, or other } \\
\text { assessments }\end{array}$} \\
\hline \multicolumn{4}{|c|}{$\begin{array}{l}292 \text { subjects underwent the first brain MRI, carotid ultrasonography, } \\
\text { assessment of risk factors, and cognitive function testing }\end{array}$} \\
\hline & & \multicolumn{2}{|c|}{$\overline{53 \text { failed to obtain ABPM data }}$} \\
\hline & & \multicolumn{2}{|c|}{31 refused the second MRI } \\
\hline & \multicolumn{3}{|c|}{$\begin{array}{l}3 \text { subjects were excluded because of atrial } \\
\text { fibrillation and } 17 \text { were excluded with poor } \\
\text { recordings on ABPM }\end{array}$} \\
\hline \multicolumn{4}{|c|}{$\begin{array}{c}190 \text { subjects ( } 85 \text { men, } 105 \text { women) underwent } \\
\text { a second brain MRI } 4 \text { years later }\end{array}$} \\
\hline & \multicolumn{3}{|c|}{21 subjects refused the second MMSE } \\
\hline $\begin{array}{l}169 \\
\text { a se }\end{array}$ & $\begin{array}{l}\text { ects }(76 \text { men } \\
\text { d cognitive fu }\end{array}$ & $\begin{array}{l}3 \text { women ) un } \\
\text { tion test } 4 \text { ye }\end{array}$ & $\begin{array}{l}\text { rwent } \\
\text { later }\end{array}$ \\
\hline
\end{tabular}

Figure 1 Flow chart showing the protocol and exclusion of individuals in this study.

persons living in Sagae City, Yamagata Prefecture, Japan. Sagae City has four areas, and all persons of the appropriate age in each area were invited to participate in this study (227 men and 263 women) (Figure 1). Among these 490 residents, individuals with contraindications to MRI or who refused examination were excluded. The remaining 292 (59.6\%) persons were included in this study. Each participant underwent ABPM, brain MRI, cognitive testing, electrocardiography and ultrasonographic evaluation of the carotid arteries at baseline; brain MRI and cognitive testing were performed again 4 years later. During a 4-year period, clinical decisions regarding drug therapy were determined by the primary care physician of each participant. Eighty-two individuals with missing data and three with atrial fibrillation were excluded. Seventeen individuals without good technical quality of ambulatory BP recording (at least $60 \%$ of valid readings on ambulatory $\mathrm{BP}$ ) were excluded, and the data from the remaining 190 (85 men, 115 women) were included in the analyses. Written informed consent was obtained from the participants, and this study was approved by the Medical Ethics Committee of the Yamagata University School of Medicine.

\section{Evaluation of cardiovascular risk factors}

Hypertension was defined as casual BP $\geqslant 140 / 90 \mathrm{~mm} \mathrm{Hg}$ or current use of antihypertensive agents. Serum total cholesterol, high-density lipoprotein cholesterol, triglyceride, fasting plasma glucose and hemoglobin Alc levels were obtained after an overnight fast. Participants were defined as having hyperlipidemia if they had a total cholesterol level $\geqslant 220 \mathrm{mg} \mathrm{dl}^{-1}$, a triglyceride level $\geqslant 150 \mathrm{mg} \mathrm{dl}^{-1}$ or were taking medication for hyperlipidemia. Furthermore, participants without a history of diabetes mellitus underwent a 75-g oral glucose tolerance test, and diabetes was diagnosed if fasting glucose was $\geqslant 126$ $\mathrm{mg} \mathrm{dl} l^{-1}$ or the glucose level at $2 \mathrm{~h}$ after the 75 -g oral glucose tolerance test was $\geqslant 200 \mathrm{mg} \mathrm{dl}^{-1}$, according to the World Health Organization criteria. ${ }^{15}$

\section{Assessment of brain MRI and definition of cerebral SVD}

The cerebral SVD of each participant was evaluated by MRI by using a $0.5-\mathrm{T}$ scanner (Flex Art; Toshiba, Tokyo, Japan). Axial T1-weighted, T2-weighted and fluid-attenuated inversion recovery images with 6-mm slices were obtained for each participant. We considered there to be cerebral SVD if the MRI showed the following: (1) WMLs, defined as at least one focal lesion in the cerebral white matter with corresponding high signal intensity on fluid-attenuated inversion recovery images or (2) lacunae, defined as a $3-15-\mathrm{mm}$ diameter area of high signal intensity on T2-weighted images with corresponding low signal intensity on T1-weighted images. WMLs often coexist with lacunae, and both can affect cognitive decline in elderly persons; ${ }^{1-3}$ hence, we examined the association of ambulatory HR and the progression of SVD using both lesions. If any WMLs or lacunae were found on the second MRI that were not visible on the first, participants were defined as showing progression of cerebral SVD.

A single trained physician (MW), who was blinded to the clinical details, evaluated the presence of SVD based on brain MRI. We used the Fazekas grade to evaluate the severity of WMLs because this grade has been shown to reflect the pathological severity of cerebral SVD in postmortem examinations. ${ }^{16}$ When we re-evaluated MRI $(n=100)$, the reproducibility (weighted $\kappa)$ of the MRI findings was good for WML grade $(\kappa=0.86)$ and moderate for lacunae $(\kappa=0.68)$.

\section{Definitions of HR variability, BP variability and nocturnal dipping of HR}

We performed ABPM on a weekday using an automated system (FB-250; Fukuda Denshi, Tokyo, Japan) that records BP and HR using an oscillometric method. The participants continued their normal daily activities during the ambulatory BP measurements. BP and HR were measured every 30 min during the day and every $60 \mathrm{~min}$ at night, as previously reported. ${ }^{17}$ People with systolic BP $>260 \mathrm{~mm} \mathrm{Hg}$ or $<70 \mathrm{~mm} \mathrm{Hg}$ or with diastolic BP $>150 \mathrm{~mm} \mathrm{Hg}$ or $<70 \mathrm{~mm} \mathrm{Hg}$ were excluded. Based on a previous study, daytime and nighttime episodes were defined as occurring from 08:00 to 22:00 $\mathrm{h}$ and from 00:00 to 06:00 h, respectively. ${ }^{18} \mathrm{HR}$ variability was estimated by the s.d. and the root mean square of successive differences (RMSSD). ${ }^{19}$ We calculated the RMSSD according to the following formula:

$$
\text { RMSSD }=\sqrt{\frac{1}{N-1} \sum_{K=1}^{N-1}\left|\mathrm{HR}_{K-1}-\mathrm{HR}_{K}\right|^{2}}
$$

In this formula, $N$ is the number of valid BP measurements, and $K$ is the order of measurements from the ABPM data corresponding to each participant. Furthermore, nocturnal HR dipping was calculated as follows: (mean HR in daytime-mean HR in the nighttime) / (mean HR in the daytime). Nondipping HR was defined as nocturnal HR dipping $<0.1$, according to a previous study. ${ }^{20}$ In addition, BP variability was estimated by s.d. and average real variability. ${ }^{21}$

\section{Assessment of carotid atherosclerosis}

The ultrasonographic assessment of the longitudinal and transverse views of both the common and internal carotid arteries was performed. The plaque score was calculated by summing the maximum thickness of the intima-media complex, as reported previously (Supplementary File 1). ${ }^{22}$

\section{Cognitive function testing}

The cognitive function of participants was assessed by the mini-mental state examination. The mini-mental state examination was performed again 4 years later to evaluate cognitive changes in the same participants. We compared baseline and follow-up mini-mental state examination scores in each participant, and a decrease of two or more points in mini-mental state examination during 4 years was defined as cognitive decline, as described in a previous study. ${ }^{23}$

\section{Statistical analysis}

Standard descriptive statistical analyses were performed. The $\chi^{2}$-test was used to compare proportions, and the unpaired $t$ test or Mann-Whitney $U$ test was used to compare two groups. The Jonckheere-Terpstra trend test was used to assess whether the monotonic trend of nocturnal HR dipping was dependent on the quartiles of indices of HR variability. Thereafter, we performed logistic regression analysis to determine whether the indices of HR variability were independently associated with the progression of SVD and cognitive decline. Probability values were two-tailed, and $P<0.05$ was considered statistically significant. All analyses were performed with $\mathrm{R}$ for Windows version 3.0.1 (www.r-project.org). 
Table 1 Baseline characteristics of all of the subjects, and of subjects with and without progression of SVD

\begin{tabular}{|c|c|c|c|c|}
\hline & \multirow{2}{*}{$\begin{array}{c}\text { All subjects } \\
\mathrm{n}=190\end{array}$} & \multicolumn{3}{|c|}{ Progression of SVD } \\
\hline & & No $(n=75)$ & Yes $(n=115)$ & P-value \\
\hline Age, years & $70.9 \pm 0.9$ & $71.0 \pm 0.8$ & $70.9 \pm 0.9$ & 0.57 \\
\hline Male, n (\%) & $85(44.7)$ & $36(48.0)$ & $49(42.6)$ & 0.47 \\
\hline Hypertension, n (\%) & $142(74.7)$ & 55 (73.3) & $87(75.7)$ & 0.72 \\
\hline Casual systolic BP, mm Hg & $143 \pm 17$ & $142 \pm 16$ & $144 \pm 18$ & 0.40 \\
\hline Casual diastolic BP, mm Hg & $82 \pm 11$ & $82 \pm 10$ & $82 \pm 11$ & 0.98 \\
\hline Hyperlipidemia, n (\%) & $84(44.2)$ & $35(46.7)$ & $49(42.6)$ & 0.58 \\
\hline Total cholesterol, $\mathrm{mg} \mathrm{dl}^{-1}$ & $203 \pm 31$ & $201 \pm 30$ & $204 \pm 32$ & 0.46 \\
\hline $\mathrm{TG}, \mathrm{mg} \mathrm{dl^{-1 }}$ & $106 \pm 59$ & $101 \pm 55$ & $110 \pm 61$ & 0.12 \\
\hline $\mathrm{HDL}-\mathrm{C}, \mathrm{mg} \mathrm{dl}^{-1}$ & $61 \pm 15$ & $62 \pm 17$ & $61 \pm 14$ & 0.93 \\
\hline $\begin{array}{l}\text { Fasting plasma glucose, } \\
\mathrm{mg} \mathrm{dl}^{-1}\end{array}$ & $104 \pm 21$ & $104 \pm 19$ & $104 \pm 22$ & 0.96 \\
\hline HbAlc (NGSP), \% & $5.6 \pm 0.7$ & $5.6 \pm 0.7$ & $5.7 \pm 0.7$ & 0.41 \\
\hline $\mathrm{DM}, \mathrm{n}(\%)$ & $30(15.8)$ & $9(12.0)$ & $21(18.3)$ & 0.25 \\
\hline Smoking, n (\%) & $56(29.5)$ & $25(33.3)$ & $31(27.0)$ & 0.35 \\
\hline Alcohol drinking, n (\%) & $48(25.3)$ & $21(28.0)$ & $27(23.5)$ & 0.48 \\
\hline BMI & $24.3 \pm 3.1$ & $24.3 \pm 3.1$ & $24.3 \pm 3.1$ & 0.84 \\
\hline Carotid artery plaque score & $2.6(3.2)$ & $2.4(3.2)$ & $2.7(3.3)$ & 0.73 \\
\hline eGFR, $\mathrm{ml} \mathrm{min}-1$ per $1.73 \mathrm{~m}^{2}$ & $79 \pm 16$ & $78 \pm 16$ & $80 \pm 16$ & 0.36 \\
\hline $\begin{array}{l}\text { Presence of lacunar } \\
\text { infarction, } n(\%)\end{array}$ & $57(30.0)$ & $16(21.3)$ & $41(35.7)$ & 0.01 \\
\hline \multicolumn{5}{|l|}{ Fazekas grade } \\
\hline $0, \mathrm{n}(\%)$ & 34 (17.9) & $18(24.0)$ & 16 (13.9) & 0.08 \\
\hline $1, \mathrm{n}(\%)$ & $98(51.6)$ & $44(58.7)$ & $54(47.0)$ & 0.11 \\
\hline $2, \mathrm{n}(\%)$ & $41(21.6)$ & $9(12.0)$ & $32(27.8)$ & $<0.01$ \\
\hline $3, \mathrm{n}(\%)$ & $17(8.9)$ & $4(5.3)$ & $13(11.3)$ & 0.16 \\
\hline MMSE score & $26.4 \pm 2.4$ & $26.5 \pm 2.6$ & $26.3 \pm 2.3$ & 0.39 \\
\hline Cognitve decline, $\mathrm{n}(\%)$ & $60(35.5)$ & $20(31.3)$ & $40(38.1)$ & 0.54 \\
\hline $\begin{array}{l}\text { Anti-hypertensive } \\
\text { medication, n (\%) }\end{array}$ & $84(43.5)$ & $31(40.8)$ & $53(45.3)$ & 0.52 \\
\hline $\mathrm{CCB}, \mathrm{n}(\%)$ & $53(27.0)$ & $21(28.0)$ & $32(27.8)$ & 0.98 \\
\hline ARB, n (\%) & $27(14.2)$ & $12(16.3)$ & $15(15.8)$ & 0.57 \\
\hline ACEI, n (\%) & $14(7.4)$ & $8(8.4)$ & $6(6.3)$ & 0.17 \\
\hline Diuretics, n (\%) & $10(5.3)$ & $3(4.0)$ & $7(6.1)$ & 0.74 \\
\hline$\alpha$-blocker, n (\%) & $4(2.1)$ & $1(1.3)$ & $3(2.6)$ & 1.00 \\
\hline$\beta$-blocker, n (\%) & $11(5.8)$ & $5(6.7)$ & $6(5.2)$ & 0.75 \\
\hline$\alpha \beta$-blocker, n (\%) & $4(2.1)$ & $2(2.7)$ & $2(1.7)$ & 0.65 \\
\hline
\end{tabular}

Abbreviations: $\mathrm{ACE}$, angiotensin-converting enzyme inhibitor; $\mathrm{ARB}$, angiotensin receptor blocker; BMI, body mass index; CCB, calcium channel blocker; DM, diabetes mellitus; eGFR, estimated glomerular filtration rate; $\mathrm{HbAlc}$, hemoglobin $\mathrm{Alc}$; $\mathrm{HDL}-\mathrm{C}$, high-density lipoprotein cholesterol; MMSE, mini-mental state examination; NGSP, National Glycohemoglobin Standardization Program; OGTT, oral glucose torelance test; SVD, small-vessel disease; TG, triglycerides. Descriptive statistics are presented as mean + s.d.

${ }^{*} P<0.05,{ }^{* *} P<0.01$.

\section{RESULTS}

The baseline characteristics of the participants are shown in Table 1. There were no significant differences in baseline characteristics between the participants included in the analyses and the participants who were excluded (Supplementary File 2). One hundred and fifteen participants showed progression of SVD at the second MRI. We did not find significant differences in clinical characteristics between participants with and without progression of SVD, including a difference in the prevalence of hypertension or casual BP values.

The results of ambulatory BP and HR indices in all participants and in participants with and without progression of SVD after the second MRI are shown in Table 2. No significant differences in maximum,
Table 2 Comparison of HR variability indices in all of the subjects and in subjects with/without SVD

\begin{tabular}{|c|c|c|c|c|}
\hline & \multirow{2}{*}{$\begin{array}{c}\text { All subjects } \\
\mathrm{n}=190\end{array}$} & \multicolumn{3}{|c|}{ Progression of SVD } \\
\hline & & No $(\mathrm{n}=75)$ & Yes $(n=115)$ & P-value \\
\hline \multicolumn{5}{|l|}{$24 h$} \\
\hline \multicolumn{5}{|l|}{ Systolic BP ( $\mathrm{mm} \mathrm{Hg})$} \\
\hline Mean & $137 \pm 15$ & $136 \pm 14$ & $137 \pm 15$ & 0.57 \\
\hline s.d. & $17.9 \pm 4.2$ & $17.3 \pm 4.0$ & $18.3 \pm 4.3$ & 0.14 \\
\hline ARV & $15.5 \pm 3.7$ & $14.9 \pm 3.5$ & $15.9 \pm 3.7$ & 0.052 \\
\hline \multicolumn{5}{|l|}{ Diastolic BP ( $\mathrm{mm} \mathrm{Hg})$} \\
\hline Mean & $82 \pm 8$ & $83 \pm 8$ & $82 \pm 8$ & 0.55 \\
\hline s.d. & $15.2 \pm 3.8$ & $14.6 \pm 3.2$ & $15.6 \pm 4.1$ & 0.07 \\
\hline ARV & $13.9 \pm 4.3$ & $13.7 \pm 3.9$ & $14.0 \pm 4.6$ & 0.74 \\
\hline \multicolumn{5}{|l|}{$H R$ (b.p.m.) } \\
\hline Mean & $68 \pm 7$ & $67 \pm 7$ & $69 \pm 7$ & 0.10 \\
\hline s.d. & $11.1 \pm 3.4$ & $10.6 \pm 3.1$ & $11.4 \pm 3.6$ & 0.29 \\
\hline RMSSD & $12.1 \pm 4.6$ & $11.3 \pm 4.4$ & $12.5 \pm 4.6$ & 0.09 \\
\hline \multicolumn{5}{|l|}{ Daytime } \\
\hline \multicolumn{5}{|l|}{ Systolic BP $(\mathrm{mm} \mathrm{Hg})$} \\
\hline Mean & $140 \pm 14$ & $140 \pm 14$ & $141 \pm 15$ & 0.65 \\
\hline s.d. & $16.8 \pm 4.3$ & $15.9 \pm 4.1$ & $17.5 \pm 4.4$ & 0.01 \\
\hline ARV & $16.1 \pm 4.5$ & $15.2 \pm 4.4$ & $16.7 \pm 4.4$ & 0.02 \\
\hline \multicolumn{5}{|l|}{ Diastolic BP $(\mathrm{mm} \mathrm{Hg})$} \\
\hline Mean & $85 \pm 9$ & $85 \pm 9$ & $84 \pm 9$ & 0.57 \\
\hline s.d. & $14.9 \pm 4.1$ & $14.4 \pm 3.8$ & $15.2 \pm 4.3$ & 0.16 \\
\hline ARV & $15.1 \pm 5.3$ & $14.9 \pm 5.2$ & $15.2 \pm 5.4$ & 0.72 \\
\hline \multicolumn{5}{|l|}{$H R$ (b.p.m.) } \\
\hline Mean & $71 \pm 8$ & $70 \pm 8$ & $72 \pm 8$ & 0.09 \\
\hline s.d. & $10.2 \pm 3.6$ & $9.9 \pm 3.4$ & $10.4 \pm 3.8$ & 0.51 \\
\hline RMSSD & $12.8 \pm 5.4$ & $12.3 \pm 5.2$ & $13.1 \pm 5.5$ & 0.34 \\
\hline \multicolumn{5}{|l|}{ Nighttime } \\
\hline \multicolumn{5}{|l|}{ Systolic BP $(\mathrm{mm} \mathrm{Hg})$} \\
\hline Mean & $125 \pm 18$ & $124 \pm 17$ & $126 \pm 19$ & 0.53 \\
\hline s.d. & $11.4 \pm 4.7$ & $11.3 \pm 4.3$ & $11.4 \pm 4.9$ & 0.95 \\
\hline ARV & $12.9 \pm 4.9$ & $12.8 \pm 5.1$ & $12.9 \pm 4.8$ & 0.85 \\
\hline \multicolumn{5}{|l|}{ Diastolic BP ( $\mathrm{mm} \mathrm{Hg})$} \\
\hline Mean & $74 \pm 10$ & $74 \pm 10$ & $73 \pm 10$ & 0.40 \\
\hline s.d. & $9.0 \pm 4.3$ & $8.6 \pm 3.4$ & $9.3 \pm 4.7$ & 0.59 \\
\hline ARV & $10.2 \pm 4.7$ & $10.3 \pm 4.1$ & $10.1 \pm 5.0$ & 0.57 \\
\hline \multicolumn{5}{|l|}{$H R$ (b.p.m.) } \\
\hline Mean & $58 \pm 7$ & $58 \pm 7$ & $59 \pm 7$ & 0.36 \\
\hline s.d. & $4.7 \pm 3.1$ & $4.3 \pm 2.5$ & $5.0 \pm 3.5$ & 0.36 \\
\hline RMSSD & $6.6 \pm 4.0$ & $5.6 \pm 2.8$ & $7.3 \pm 4.5$ & 0.02 \\
\hline Nocturnal HR dipping, \% & $17.4 \pm 7.5$ & $16.8 \pm 7.7$ & $17.8 \pm 7.4$ & 0.29 \\
\hline Nondipping $\mathrm{HR}, \mathrm{n}(\%)$ & $24(12.6)$ & $12(16.0)$ & $12(10.4)$ & 0.26 \\
\hline
\end{tabular}

Abbreviations: ARV, average real variability; BP, blood pressure; b.p.m., beats per minite; $\mathrm{HR}$ heart rate; HRV, heart rate variability; RMSSD, root mean square of successive differences; SVD, small-vessel disease.

Descriptive statistics are presented as mean \pm s.d. $* P<0.05$.

minimum and mean ambulatory BP were identified between the two groups. However, the nighttime RMSSD of participants with progression of SVD was significantly higher than the nighttime RMSSD of participants without progression of SVD $(P=0.02)$.

We subsequently assessed the association of $\mathrm{HR}$ variability in nighttime and nocturnal HR dipping. Nocturnal HR dipping was less in the top quartiles of nighttime HR variability (s.d. and RMSSD) than 
a

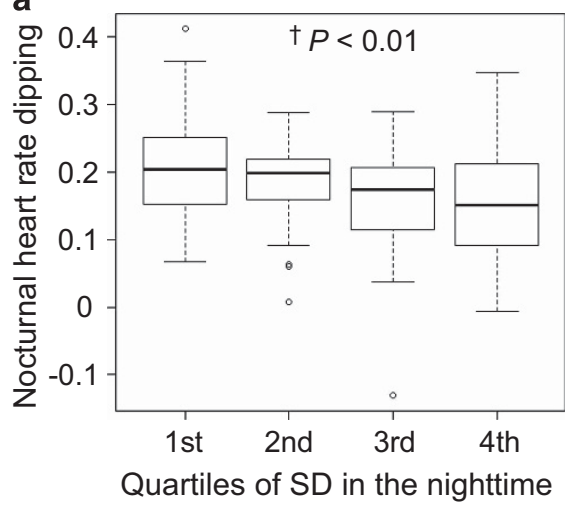

b

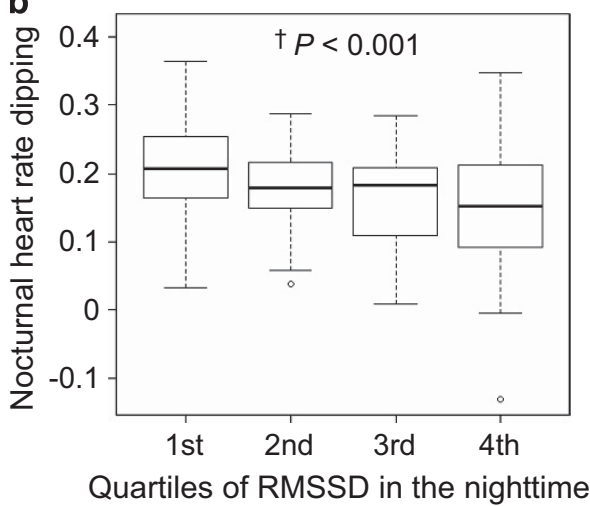

Figure 2 Association between nocturnal dipping of HR and quartiles of HRV. Panels (a) and (b) represent the s.d. and RMSSD in nighttime HR, respectively. $\mathrm{HR}$, heart rate; RMSSD, root mean square of successive differences; ${ }^{\dagger}$ Jonckheere-Terpstra trend test.

Table 3 Odds ratios of HR and HR variability indices for progression of SVD

\begin{tabular}{|c|c|c|c|c|c|}
\hline & & \multicolumn{2}{|c|}{ Univariate analysis } & \multicolumn{2}{|c|}{ Mulitivariate analysis } \\
\hline & & OR $(95 \% \mathrm{Cl})$ & P-value & OR $(95 \% \mathrm{Cl})$ & P-value \\
\hline Mean & 10 b.p.m. increment & $1.36(0.90-2.05)$ & 0.15 & & \\
\hline s.d. & 1 b.p.m. increment & $1.07(0.98-1.17)$ & 0.11 & & \\
\hline RMSSD & 1 b.p.m. increment & $1.06(0.99-1.14)$ & 0.08 & & \\
\hline Mean & 10 b.p.m. increment & $1.32(0.91-1.93)$ & 0.15 & & \\
\hline s.d. & 1 b.p.m. increment & $1.04(0.96-1.13)$ & 0.32 & & \\
\hline RMSSD & 1 b.p.m. increment & $1.03(0.97-1.09)$ & 0.32 & & \\
\hline \multicolumn{6}{|l|}{ Nighttime } \\
\hline Mean & 10 b.p.m. increment & $1.18(0.77-1.81)$ & 0.46 & & \\
\hline
\end{tabular}

Abbreviations: ABPM, ambulatory blood pressure monitoring; b.p.m., beats per minite; $\mathrm{Cl}$, confidence interval; HR, heart rate; OR, odds ratio; RMSSD, root mean square of successive differences. Multivariate analysis included age, sex, mean systolic blood pressure in ABPM, mean HR in ABPM, conventional risk factors (hypertension, diabetes mellitus and hyperlipidemia), smoking, alcohol drinking, Fazekas grade and plaque scores of catorid arteries.

drinking, Fazz

in the other quartiles, and the Jonckheere-Terpstra trend test showed a monotonic trend of nocturnal HR dipping that was dependent on the quartiles of indices of nighttime HR variability (Figures $2 \mathrm{a}$ and $\mathrm{b}$; $P<0.01, P<0.001$, respectively).

We evaluated the odds ratios (ORs) of the HR variability indices for the likelihood of progression of SVD by logistic regression analysis (Table 3). One b.p.m. increment of nighttime RMSSD was significantly associated with the progression of SVD, even after adjustment for age, sex, mean systolic BP, mean HR, conventional risk factors (hypertension, diabetes mellitus and hyperlipidemia), smoking and alcohol drinking $(\mathrm{OR}=1.16,95 \%$ confidence interval $(\mathrm{CI})=1.05-1.27, P<0.01)$.

At the second cognitive test, cognitive decline was recognized in 60 participants $(35.5 \%, 60 / 169)$. The results of the ambulatory BP and HR indices in all participants and in participants with and without cognitive decline over during 4 years are shown in Supplementary File 3. Several BP indices were significantly higher in the participants with cognitive decline than in the participants without cognitive decline, but the s.d. of 24-h and daytime HR showed a borderline significance.

We assessed the ORs of HR variability indices for the likelihood of cognitive decline by logistic regression analysis (Table 4 ). In multivariate analysis, the s.d. of 24-h and daytime HR remained significant, even after the adjustment for confounding factors ( $O R=1.13,95 \%$ $\mathrm{CI}=1.01-1.26, \quad P=0.03 ; \mathrm{OR}=1.11,95 \% \mathrm{CI}=1.01-1.22, \quad P=0.04$, respectively).

\section{DISCUSSION}

In this study, we showed that nighttime $\mathrm{HR}$ variability in ABPM at baseline was independently related to an increased risk of SVD progression. Furthermore, increased nighttime HR variability was suggested to correlate with blunted nocturnal HR dipping. However, we could not demonstrate a significant association between increased nighttime HR variability and cognitive decline.

This work is believed to be the first longitudinal cohort study showing that raised nighttime HR variability measured by ABPM is 
Table 4 Odds ratios of HR and HR variability indices for cognitive decline

\begin{tabular}{|c|c|c|c|c|c|}
\hline & & \multicolumn{2}{|c|}{ Univariate analysis } & \multicolumn{2}{|c|}{ Mulitivariate analysis } \\
\hline & & OR $(95 \% \mathrm{Cl})$ & P-value & OR $(95 \% \mathrm{Cl})$ & P-value \\
\hline \multicolumn{6}{|l|}{$24 h$} \\
\hline Mean & 10 b.p.m. increment & $1.23(0.80-1.88)$ & 0.35 & & \\
\hline s.d. & 1 b.p.m. increment & $1.11(1.00-1.22)$ & $0.04^{*}$ & $1.13(1.01-1.26)$ & $0.03^{*}$ \\
\hline RMSSD & 1 b.p.m. increment & $1.08(1.00-1.15)$ & $0.04^{*}$ & $1.08(1.00-1.16)$ & 0.050 \\
\hline \multicolumn{6}{|l|}{ Daytime } \\
\hline Mean & 10 b.p.m. increment & $1.20(0.82-1.78)$ & 0.35 & & \\
\hline s.d. & 1 b.p.m. increment & $1.10(1.00-1.20)$ & $0.04^{*}$ & $1.11(1.01-1.22)$ & $0.04^{*}$ \\
\hline RMSSD & 1 b.p.m. increment & $1.06(0.99-1.13)$ & 0.053 & $1.06(0.95-1.13)$ & 0.07 \\
\hline \multicolumn{6}{|l|}{ Nighttime } \\
\hline Mean & 10 b.p.m. increment & $1.19(0.76-1.87)$ & 0.45 & & \\
\hline s.d. & 1 b.p.m. increment & $1.11(1.00-1.22)$ & 0.051 & $1.10(0.99-1.23)$ & 0.08 \\
\hline RMSSD & 1 b.p.m. increment & $1.03(0.96-1.12)$ & 0.41 & & \\
\hline
\end{tabular}

Abbreviations: b.p.m., beats per minute; $\mathrm{Cl}$, confidence interval; HR, heart rate; MMSE, mini-mental state examination; OR, odds ratio; RMSSD, root mean square of successive differences. Cognitive decline was defined as a drop in the MMSE score of at least two points.

Multivariate analysis included age, sex, mean systolic blood pressure, mean HR, conventional risk factors (hypertension, diabetes mellitus and hyperlipidemia), smoking, alcohol drinking, Fazekas grade and plaque scores of catorid arteries.

${ }^{*} P<0.05$.

linked to SVD progression in the brain. Increased HR in ABPM is associated with SVD; however, the potential relationship between HR variability and SVD progression has seldom been explored. ${ }^{11-14}$ A few previous studies failed to identify a link between HR in ABPM and WMLs in patients with hypertension ${ }^{13}$ or community-dwelling people. ${ }^{11}$ However, Sierra et al. ${ }^{12}$ showed a relationship between advanced WMLs and a sustained increase in nighttime $H R$ in hypertensive patients. A recent study showed an association between ambulatory 24-h HR and advanced WMLs in subacute ischemic stroke patients. ${ }^{14}$ However, all of these previous studies were cross-sectional by design; therefore, they could not verify a causal relationship between ambulatory HR and SVD.

Paradoxically, reduced HR variability is associated with increased risk of cardiovascular morbidity and mortality. ${ }^{24}$ Our findings support the interaction between increased nighttime $\mathrm{HR}$ variability and nocturnal HR nondipping status. Blunted nocturnal HR dipping may represent a state of sympathetic overdrive and is indicated as a risk factor for cardiovascular events in patients with hypertension. ${ }^{20}$ Eguchi et al. ${ }^{19}$ reported the association of raised nighttime HR variability in ABPM and increased risk of cardiovascular disease in type 2 diabetes patients, suggesting that increased HR variability caused by predominance of sympathetic tone might facilitate the onset of cardiovascular events. Scierra et al. ${ }^{25}$ recently reported that increased HR and HR variability at night measured by ABPM were independently related to resistant hypertension, which was considered to be caused by the involvement of sympathetic overdrive. Nighttime HR variability potentially reflects an imbalance between sympathetic and parasympathetic activities, and autonomic imbalance is speculated to cause SVD progression. An increase in pulsatile flow on the vascular wall may impose mechanical stress on the endothelium, which can result in endothelial dysfunction over the course of many years. ${ }^{26}$ The vascular architecture of the deep brain regions lacks anastomoses; therefore, impairment of autoregulation in the rigid vessels could contribute to hypoperfusion, leading to brain damage due to impaired vasodilation. ${ }^{27}$

An increase in nighttime physical activity accompanied by sleep apnea could be another explanation for our results. ${ }^{28}$ An increasing body of evidence shows that sleep apnea syndrome is linked to cerebral SVD, and this brain damage is related to the severity of sleep apnea syndrome. ${ }^{29}$

In contrast to the association between nighttime HR variability and progression of SVD, we failed to find an independent relationship between nighttime HR variability and cognitive decline. However, the use of more sensitive cognitive function tests and larger sample sizes might detect a significant relationship between ambulatory HR and cognitive decline. Previous studies have suggested that the association between cognitive decline and BP is stronger in studies with a long follow-up period and with BP measurements in midlife. ${ }^{30}$ The association of ambulatory HR and cognitive decline is complex, and an earlier and longer exposure to high HR variability is potentially related to higher levels of brain damage.

This study had several limitations. First, we were not able to quantify the changes in SVD. WML volumes assessed by quantitative techniques are superior to a visual rating scale for assessing SVD. ${ }^{31}$ Second, variations in antihypertensive agents might have affected HR variability, thus affecting the associations among HR, SVD and cognitive function. Third, the fixed-time method of measuring ambulatory HR potentially failed to detect the differences in shortterm HR variability, especially during sleep, because HR measurements were only obtained at 60 -min intervals. HR variability measured by Holter electrocardiography has been accepted as the international standard.

The current guidelines of the European Society of Hypertension suggest that high HR should be included when evaluating the cardiovascular risk profile. ${ }^{32}$ However, the clinical utility of measuring $\mathrm{HR}$ is incompletely clarified because no precise cut-off value is available to physicians for the prevention of cerebrovascular disease. Further prospective studies with an appropriate sample size are needed to evaluate the relationships among HR variability, SVD progression and cognitive decline in the community-dwelling elderly population.

\section{CONFLICT OF INTEREST}

The authors declare no conflict of interest. 
1 Pantoni L. Cerebral small vessel disease: from pathogenesis and clinical characteristics to therapeutic challenge. Lancet Neurol 2010; 9: 689-701.

2 O'Brien JT, Erkinjuntti T, Reisberg B, Roman G, Sawada T, Pantoni L, Bowler JV, Ballard C, DeCarli C, Gorelick PB, Rockwood K, Burns A, Gauthier S, DeKosky ST. Vascular cognitive impairment. Lancet Neurol 2003; 2: 89-98.

3 The LADIS study group. 2001-2011: a decade of the LADIS (Leukoaraiosis and Disability) Study: what have we learned about white matter changes and small-vessel disease? Cerebrovasc Dis 2011; 32: 577-588.

4 Kario K. Proposal of a new strategy for ambulatory blood pressure profile-based management of resistant hypertension in the era of renal denervation. Hypertens Res 2013; 36: 478-484.

5 Okada H, Fukui M, Tanaka M, Matsumoto S, Mineoka Y, Nakanishi N, Tomiyasu K, Nakano K, Hasegawa G, Nakamura N. Visit-to-visit variability in systolic blood pressure is a novel risk factor for the progression of coronary artery calcification. Hypertens Res 2013; 36: 996-999.

6 Fukui M, Ushigome E, Tanaka M, Hamaguchi M, Tanaka T, Atsuta H, Ohnishi M, Oda Y, Hasegawa G, Nakamura N. Home blood pressure variability on one occasion is a nove factor associated with arterial stiffness in patients with type 2 diabetes. Hypertens Res 2013; 36: 219-225.

7 Yamaguchi Y, Wada M, Sato H, Nagasawa H, Koyama S, Takahashi Y, Kawanami T, Kato $\mathrm{T}$. Impact of ambulatory blood pressure variability on cerebral small vessel disease progression and cognitive decline in community-based elderly Japanese. $A m$ Hypertens 2014; 27: 1257-1267.

8 Palatini P, Reboldi G, Beilin LJ, Eguchi K, Imai Y, Kario K, Ohkubo T, Pierdomenico SD, Saladini F, Schwartz JE, Wing L, Verdecchia P. Predictive value of night-time heart rate for cardiovascular events in hypertension. The ABP-International study. Int J Cardiol 2013; 168: 1490-1495.

9 Palatini P. Role of elevated heart rate in the development of cardiovascular disease in hypertension. Hypertension 2011; 58: 745-750.

10 Ben-Dov IZ, Kark JD, Ben-Ishay D, Mekler J, Ben-Arie L, Bursztyn M. Blunted heart rate dip during sleep and all-cause mortality. Arch Intern Med 2007; 167: 2116-2121

11 Goldstein IB, Bartzokis G, Hance DB, Shapiro D. Relationship between blood pressure and subcortical lesions in healthy elderly people. Stroke 1998; 29: 765-772.

12 Sierra C, de La Sierra A, Mercader J, Gómez-Angelats E, Urbano-Márquez A, Coca A Silent cerebral white matter lesions in middle-aged essential hypertensive patients. $J$ Hypertens 2002; 20: 519-524.

13 van Boxtel MP, Henskens LH, Kroon AA, Hofman PA, Gronenschild EH, Jolles J, de Leeuw PW. Ambulatory blood pressure, asymptomatic cerebrovascular damage and cognitive function in essential hypertension. J Hum Hypertens 2006; 20: 5-13.

14 Kwon HS, Lim YH, Kim HY, Kim HT, Kwon HM, Lim JS, Lee YJ, Kim JY, Kim YS. Association of ambulatory blood pressure and heart rate with advanced white matter lesions in ischemic stroke patients. Am J Hypertens 2014; 27: 177-183.

15 Alberti KG, Zimmet PZ. Definition, diagnosis and classification of diabetes mellitus and its complications. Part 1: diagnosis and classification of diabetes mellitus provisional report of a WHO consultation. Diabet Med 1998; 15: 539-553.

16 Fazekas F, Kleinert R, Offenbacher H, Schmidt R, Kleinert G, Payer F, Radner H, Lechner H. Pathologic correlates of incidental MRI white matter signal hyperintensities. Neurology 1993; 43: 1683-1689.

17 Birns J, Morris R, Jarosz J, Markus H, Kalra L. The structural and functional consequences of diurnal variations in blood pressure in treated patients with hypertensive cerebrovascular disease. J Hypertens 2009; 27: 1042-1048.
18 Bilo G, Giglio A, Styczkiewicz K, Caldara G, Maronati A, Kawecka-Jaszcz K, Mancia G, Parati G. A new method for assessing 24-h blood pressure variability after excluding the contribution of nocturnal blood pressure fall. J Hypertens 2007; 25: 2058-2066.

19 Eguchi K, Schwartz JE, Pickering TG, Hoshide S, Ishikawa J, Shimada K, Kario K. Increased heart rate variability during sleep is a predictor for future cardiovascular events in patients with type 2 diabetes. Hypertens Res 2010; 33: 737-742.

20 Eguchi K, Hoshide S, Ishikawa J, Pickering TG, Schwartz JE, Shimada K, Kario K. Nocturnal nondipping of heart rate predicts cardiovascular events in hypertensive patients. J Hypertens 2009; 27: 2265-2270.

21 Mena L, Pintos S, Queipo NV, Aizpúrua JA, Maestre G, Sulbarán T. A reliable index for the prognostic significance of blood pressure variability. J Hypertens 2005; 23: 505-511.

22 Handa N, Matsumoto M, Maeda H, Hougaku H, Ogawa S, Fukunaga R, Yoneda S, Kimura K. Kamada T. Ultrasonic evaluation of early carotid atherosclerosis. Stroke 1990; 21: 1567-1572

23 Böhm M, Cotton D, Foster L, Custodis F, Laufs U, Sacco R, Bath PM, Yusuf S, Diener HC. Impact of resting heart rate on mortality, disability and cognitive decline in patients after ischaemic stroke. Eur Heart J 2012; 33: 2804-2812.

24 Thayer JF, Yamamoto SS, Brosschot JF. The relationship of autonomic imbalance, heart rate variability and cardiovascular disease risk factors. Int J Cardiol 2010; 141: 122-131.

25 de la Sierra A, Calhoun DA, Vinyoles E, Banegas JR, de la Cruz JJ, Gorostidi M, Segura J, Ruilope LM. Heart rate and heart rate variability in resistant versus controlled hypertension and in true versus white-coat resistance. J Hum Hypertens 2014; 28 : 416-420.

26 Thorin E, Thorin-Trescases N. Vascular endothelial ageing, heartbeat after heartbeat. Cardiovasc Res 2009; 84: 24-32.

27 Wardlaw JM, Smith C, Dichgans M. Mechanisms of sporadic cerebral small vessel disease: insights from neuroimaging. Lancet Neurol 2013; 12: 483-497.

28 Isaksson H, Svanborg E. Obstructive sleep apnea syndrome in male hypertensives, refractory to drug therapy. Nocturnal automatic blood pressure measurements - an aid to diagnosis? Clin Exp Hypertens 1991; 13: 1195-1212.

29 Kim H, Yun CH, Thomas RJ, Lee SH, Seo HS, Cho ER, Lee SK, Yoon DW, Suh S, Shin C. Obstructive sleep apnea as a risk factor for cerebral white matter change in a middle-aged and older general population. Sleep 2013; 36: 709-715.

30 Tzourio C, Laurent S, Debette S. Is hypertension associated with an accelerated aging of the brain? Hypertension 2014; 63: 894-903.

31 Wardlaw JM, Smith EE, Biessels GJ, Cordonnier C, Fazekas F, Frayne R, Lindley RI, O'Brien JT, Barkhof F, Benavente OR, Black SE, Brayne C, Breteler M, Chabriat H, Decarli C, de Leeuw FE, Doubal F, Duering M, Fox NC, Greenberg S, Hachinski V, Kilimann I, Mok V, Oostenbrugge Rv, Pantoni L, Speck O, Stephan BC, Teipel S, Viswanathan A, Werring D, Chen C, Smith C, van Buchem M, Norrving B, Gorelick PB, Dichgans M. Standards for ReportIng Vascular changes on nEuroimaging (STRIVE v1). Neuroimaging standards for research into small vessel disease and its contribution to ageing and neurodegeneration. Lancet Neurol 2013; 12: 822-838.

32 Mancia G, Fagard R, Narkiewicz K, Redón J, Zanchetti A, Böhm M, Christiaens T, Cifkova R, De Backer G, Dominiczak A, Galderisi M, Grobbee DE, Jaarsma T, Kirchhof $P$, Kjeldsen SE, Laurent $S$, Manolis AJ, Nilsson PM, Ruilope LM, Schmieder RE, Sirnes PA, Sleight P, Viigimaa M, Waeber B, Zannad F. Task Force Members. 2013 ESH/ESC Guidelines for the management of arterial hypertension: The Task Force for the management of arterial hypertension of the European Society of Hypertension (ESH) and of the European Society of Cardiology (ESC). J Hypertens 2013; 31: 1281-1357.

Supplementary Information accompanies the paper on Hypertension Research website (http://www.nature.com/hr) 